\title{
Вмј Global Health Influence of travel time and distance to the hospital of care on stillbirths: a retrospective facility-based cross- sectional study in Lagos, Nigeria
}

\author{
Aduragbemi Banke-Thomas (D) , ', Cephas Ke-on Avoka (D) ,' \\ Uchenna Gwacham-Anisiobi, ${ }^{3}$ Lenka Benova ${ }^{4}$
}

To cite: Banke-Thomas A Avoka CK, Gwacham-Anisiobi U, et al. Influence of travel time and distance to the hospital of care on stillbirths: a retrospective facility-based cross-sectional study in Lagos, Nigeria. BMJ Global Health 2021:6:e007052. doi:10.1136/ bmjgh-2021-007052

Handling editor Seye Abimbola

- Additional supplemental material is published online only To view, please visit the journal online (http://dx.doi.org/10. 1136/bmjgh-2021-007052)

Received 31 July 2021 Accepted 17 September 2021

Check for updates

(c) Author(s) (or their employer(s)) 2021. Re-use permitted under CC BY-NC. No commercial re-use. See rights and permissions. Published by BMJ.

${ }^{1}$ LSE Health, London School of Economics and Political Science, London, UK

${ }^{2}$ Faculty of Public Health, Ghana College of Physicians and Surgeons, Accra, Ghana ${ }^{3}$ Nuffield Department of Population Health, University of Oxford, Oxford, UK

${ }^{4}$ Department of Public Health, Institute of Tropical Medicine, Antwerpen, Belgium

Correspondence to Dr Aduragbemi Banke-Thomas; a.banke-thomas@Ise.ac.uk

\section{ABSTRACT}

Introduction Access to emergency obstetric care can lead to a $45 \%-75 \%$ reduction in stillbirths. However, before a pregnant woman can access this care, she needs to travel to a health facility. Our objective in this study was to assess the influence of distance and travel time to the actual hospital of care on stillbirth.

Methods We conducted a retrospective crosssectional study of pregnant women who presented with obstetric emergencies over a year across all 24 public hospitals in Lagos, Nigeria. Reviewing clinical records, we extracted sociodemographic, travel and obstetric data. Extracted travel data were exported to Google Maps, where typical distance and travel time for period-of-day they travelled were extracted. Multivariable logistic regression was conducted to determine the relative influence of distance and travel time on stillbirth

Results 0 3278 births, there were 408 stillbirths $(12.5 \%)$. Women with livebirths travelled a median distance of $7.3 \mathrm{~km}$ (IQR 3.3-18.0) and over a median time of 24 min (IQR 12-51). Those with stillbirths travelled a median distance of $8.5 \mathrm{~km}$ (IQR 4.4-19.7) and over a median time of $30 \mathrm{~min}$ (IQR 16-60). Following adjustments, though no significant association with distance was found, odds of stillbirth were significantly higher for travel of 10-29 min (OR $2.25,95 \% \mathrm{Cl} 1.40$ to 3.63 ), 30-59 $\mathrm{min}$ (OR 2.30, $95 \% \mathrm{Cl} 1.22$ to 4.34 ) and $60-119 \mathrm{~min}$ (OR 2.35, 95\% Cl 1.05 to 5.25). The adjusted OR of stillbirth was significantly lower following booking (OR $0.37,95 \%$ $\mathrm{Cl} 0.28$ to 0.49 ), obstetric complications with mother (obstructed labour (OR $0.11,95 \% \mathrm{Cl} 0.07$ to 0.17 ) and haemorrhage (OR $0.30,95 \% \mathrm{Cl} 0.20$ to 0.46$)$ ). 0 dds were significantly higher with multiple gestations $(\mathrm{OR}$ $2.40,95 \% \mathrm{Cl} 1.57$ to 3.69 ) and referral (OR $1.55,95 \%$ Cl 1.13 to 2.12).

Conclusion Travel time to a hospital was strongly associated with stillbirth. In addition to birth preparedness, efforts to get quality care quicker to women or women quicker to quality care will be critical for efforts to reduce stillbirths in a principally urban low-income and middleincome setting.

\section{Key questions}

What is already known?

- Nigeria has a stillbirth rate of 22.2 per 1000 total births and contributes the third highest number of stillbirths globally, with over $50 \%$ happening just around the time of birth.

- Delays in reaching an appropriately equipped health facility which can render critical maternal and newborn health services contribute to poor maternal and perinatal outcomes.

- No singular study has specifically assessed the influence of travel time and distance to actual facility of care on stillbirths.

What are the new findings?

- Almost half of stillbirths occurred among women who had to travel less than $10 \mathrm{~km}$ and less than 30 min to the hospital of care.

- Though total distance was a significant factor, it was not significant after adjusting for confounders.

- After adjustments, travel time remained statistically significant for 10-29 min, 30-59 min and 60-119 min to a hospital of care.

What do the new findings imply?

- As our findings show, survival of a newborn is timesensitive and as such any actions aimed at addressing stillbirths need to focus on time of travel.

- There is also a case for strengthening referral systems to ensure that there are no unnecessary delays at first line facilities and that such facilities are equipped to be able to get pregnant women to higher level facilities in quicker time.

- Before the emergency, skilled health personnel need to use antenatal care visits to discuss travel plans with couples as part of birth preparedness.

\section{INTRODUCTION}

A United Nations Inter-Agency Group report on Child Mortality Estimation estimated that almost two million babies died in the third trimester of pregnancy across the globe in 2019. Almost all these deaths, otherwise 
known as stillbirths, occurred in low-income and middleincome countries (LMICs) (98\%) including threequarters in sub-Saharan Africa and south Asia. Though it is recognised as a 'neglected tragedy', Nigeria, third to only India and Pakistan contributes 9\% (171 428) of stillbirths annually. ${ }^{1}$ When the Sustainable Development Goals (SDGs) were declared, though there was a target set for global neonatal mortality, there was none set for stillbirth specifically. ${ }^{2}$ This necessitated the Lancet Every Newborn Study Group to recommend that national targets for stillbirth rates (SBR) be set at $\leq 10$ per 1000 total births, which should be achieved by year 2035-a target adopted by the 67th World Health Assembly. ${ }^{3}$ Nigeria currently has an SBR of 22.2 stillbirths per 1000 total births. ${ }^{1}$

Stillbirths may occur antepartum (on or after 28 weeks' gestation but before labour) or intrapartum (after the onset of labour but before birth). ${ }^{4}$ Around half of all stillbirths in sub-Saharan Africa are intrapartum, compared with about $6 \%$ in many high-income countries. ${ }^{1}$ The distinction between an antepartum and intrapartum stillbirth is based on confirmation of the presence of a fetal heart sound at the onset of labour. Where this is not available, an assessment of the skin for signs of maceration, which begins 2-12 hours after death is used to make the distinction, with death occurring in the intrapartum period also referred to as fresh stillbirth and antepartum referred to as a macerated stillbirth. ${ }^{4}$ While many antepartum stillbirths are preventable, intrapartum stillbirths, which are typically deemed to reflect quality of care during labour, are entirely preventable. ${ }^{45}$ Estimates of between $35 \%$ and $60 \%$ have been reported as proportion of intrapartum stillbirths in Nigeria. ${ }^{4}$

At a global level, the strategy to prevent adverse pregnancy outcomes, reemphasised with the SDGs, has predominantly focused on increasing access to prompt emergency obstetric care (EmOC) provided by a skilled health personnel. ${ }^{26}$ Evidence suggests that when EmOC, which is a set of nine clinical and surgical interventions including parenteral antibiotics, anticonvulsants and uterotonics, manual removal of placenta, removal of retained products, neonatal resuscitation, assisted vaginal delivery, caesarean section and blood transfusion, can lead to $45 \%-75 \%$ reduction in intrapartum stillbirths. ${ }^{67}$ However, before an expectant mother can access EmOC, she needs to travel to the health facility. Any delay in travel to reach appropriately equipped health facilities can contribute to poor pregnancy outcomes for her and her baby. ${ }^{8}$ To better understand the association between travel to health facilities and pregnancy outcomes, there is a need to accurately capture the journey including any delays experienced to reach health facilities. However, for many women, their real travel experience to care remains unknown in many LMIC health systems. ${ }^{9} 10$

Until, only a few studies have looked at influence of travel including distance and travel time on perinatal outcomes in LMICs including one that focused specifically on stillbirths. ${ }^{11-14}$ The one study that specifically assessed stillbirth was conducted in a hospital located in a north-eastern city of Nigeria and focused on travel time, not distance. ${ }^{14}$ However, distance and travel time are both important considerations, especially in urban and periurban LMIC settings, where some pregnant women could travel for a long time despite living only a short distance from the health facility, due to traffic and vice versa, due to access to motorised transport. ${ }^{9}$ The objective of our study was to assess the effect of distance and travel time from home to facility of care on stillbirth that occurred in public hospitals of Nigeria's most urbanised state, Lagos. This study was part of a larger mixed-methods study that explored the geographical accessibility of pregnant women to public hospitals in Lagos State, Nigeria.

\section{METHODS \\ Study design, setting and population}

Lagos State in the southwestern part of Nigeria has diverse geographical terrains (including land and water) and settlement types (including its central megacity, suburbs, slums and towns). While principally urban, Lagos state has some rural parts in its extreme east and west. The state has 20 local government areas and a population of approximately 26 million (estimated in 2019). ${ }^{15}$ The most common means of travel in Lagos is by road. However, in many parts of the state, the road infrastructure is poor, evidenced by presence of multiple potholes that sometimes make roads impassable for commuters. Severe traffic congestions are a common feature, with flooding during the rainy season making road conditions even worse. Road renovations are at best a stopgap and sometimes cause even more travel disruptions. ${ }^{16-18}$

Our study was a statewide multifacility retrospective cross-sectional study that identified pregnant women who presented with obstetric emergencies at one of the 24 public hospitals with capacity for $24 / 7$ all provision of EmOC services in the state. These 24 public hospitals include 20 general hospitals which are secondary health facilities with either a general obstetric unit or a dedicated Maternal Childcare Centres and four teaching hospitals which are tertiary health facilities (Details of the hospitals are in online supplemental table 1). According to the Health Facility Monitoring and Accreditation Agency, there are 1329 accredited private hospitals in Lagos. However, government health facilities manage $42 \%$ of deliveries in the state, while private health facilities take up about $28 \% .{ }^{19}$ Two studies that estimated institutional SBR in Nigerian public hospitals reported 39.6 and 61.8 per 1000 births, respectively. ${ }^{20} 21$

\section{Data collection}

We collected data from all 24 public hospitals over a 6-month period. The data collection team comprised consultant obstetricians, resident doctors and medical officers who had clinical experience working in the obstetric units of the hospitals and were familiar with the patient records system in Lagos public health facilities. 
The data collection team members were all trained on the standard operations protocol to guide data collection and ensure consistency across the different hospitals, use of the pretested online data collection tool in Google Forms and the ethical procedures guiding the research.

From clinical records of all pregnant women with gestational age of 28 weeks or more who presented with an obstetric emergency between 1 November 2018 and 30 October 2019, we obtained data on sociodemographic characteristics, obstetric history, travel to reach the health facility (including day of travel and period-of-day when journey to the facility commenced, street name of women's self-reported place of residence, referral facilities if any, the destination facility (one of the 24 public hospitals)), obstetric complication managed, mode of delivery and pregnancy outcomes. All pregnant women who presented at the obstetric emergency room and had a live or stillbirth at or after gestational age of 28 weeks were included. For the outcome, stillbirth, we aligned with WHO's definition applicable in many LMIC settings defining a stillbirth as a baby born with no signs of life at 28 weeks of pregnancy or more. ${ }^{4}$ We excluded 51 cases with perinatal deaths that occurred after the baby was born alive (early neonatal deaths), because these deaths may have more to do with quality of care, as opposed to travel to the health facility. We excluded a further 22 cases which had missing data regarding the outcome of the pregnancy or gestational age could not be established. All recorded data captured in Google Forms was subsequently exported as a Microsoft Excel file.

Additional data gathering on distance and travel time were required to fully characterise the travel to reach the hospital. Studies that estimated distance and travel time of pregnant women to reach EmOC facilities in LMIC settings have mostly been based on women's self-reports or spatial models, ${ }^{10}$ with the accuracy of both approaches questioned by several authors. ${ }^{22-25}$ Compared with spatial model estimates, distance and travel time estimates using global positioning satellite navigation software like Google Maps (Alphabet, Mountain View, California, USA) have been shown to be closer to reality in an LMIC urban setting. ${ }^{26}$ Building on this evidence, we georeferenced the place of residence, referral points and destination facility for each woman in Google Maps, based on the data extracted from their clinical records. For addresses that were not discoverable on Google Maps, we contacted local persons who were well acquainted with the neighbourhoods to check for any spelling errors and reattempted to locate the street. For pregnant women with traceable journeys (meaning location of the home address and all referral points were known), we extracted distance (in kilometres $(\mathrm{km})$ and travel time (in minute (min) for their journeys from Google Maps using the 'typical time of travel' tool for the time and day that the woman commenced her journey to the hospital, as per data extracted from the clinical records. To collect travel time estimates for the period-of-day of travel, we used specific time slots (9:00, 15:00, 18:00 and 21:00 hours for morning, afternoon, evening or night journeys, respectively). In cases in which this data was not available (27\% of the sample), we assumed the woman travelled in the afternoon (15:00 hours), as it was a midpoint estimate between the two known travel peak periods in Lagos (6:30 and 11:30 hours (morning peak period) and 15:00 and 19.30 hours (evening peak period)). ${ }^{27}$ For means of transport, we assumed that all pregnant women used motor vehicle, since private cars $(25 \%)$ and taxis $(21 \%)$ are the most popular means of transport to health facilities, emergency or otherwise, and is almost always the transport means used by pregnant women in emergency situations in Lagos, especially as motorcycles have been banned. ${ }^{92}$ In cases in which it was not possible to find specific points of travel of the women, we labelled the case as untraceable ( $4 \%$ of the sample).

\section{Data analysis}

Following data cleaning in Microsoft Excel (Microsoft Corporation, Redmond, USA), we used the extracted geocoordinates to map and visually inspect places of origin of all women with stillbirths relative to the location of public hospitals and produced maps in ArcGIS 10.6 (Esri, Redlands, California, USA). We then conducted descriptive analysis for all theoretically relevant sociodemographic and obstetric characteristics, travel path to facility and mode of delivery, indicating frequencies and percentages for categorical variables. The mean and SD as well as median and IQR for distance and travel time were computed. For interpretation, priority was given to the median values as these are known to be robust to the outliers. ${ }^{29}$ All continuous variables were subsequently converted into categorical variables.

We conducted bivariate logistic regression to test the null hypothesis that there is no statistically significant association between each of the independent variables and stillbirth. The stillbirths were subsequently categorised into fresh and macerated stillbirths as extracted from patient records, as we theorised that the fresh type was more likely related to travel, since these occurred after the onset of labour but before birth, when the woman would have been en route to a health facility. ${ }^{4}$ Where there were discrepancies in stillbirth classifications for multiple gestations (eg, one fresh and one macerated), the stillbirth status of the first baby was used in the classification. Finally, we conducted multivariate logistic regression to determine the relative influence of the independent variable categories on stillbirths while controlling for other variables. The logistic regression models were built stepwise incorporating variables that showed a statistically significant association with stillbirths as an outcome in the bivariate analysis. Four models were fitted. Model I incorporated only significant sociodemographic and obstetric variables, model II added travel distance to significant sociodemographic and obstetric variables, model III added travel time to significant socio-demographic and obstetric variables and model IV included both travel time and distance to 
significant sociodemographic and obstetric variables. We reported both $\mathrm{p}$ values and $95 \%$ CIs of ORs derived from regression coefficients to show strength of evidence and considered differences between observations as statistically significant when the $p$ value was $<0.05$. We also conducted a subgroup analysis by referral status and by stillbirth category (fresh and macerated). Missing data were excluded from the analysis.

We conducted all statistical analysis in STATA SE V.15.0 (StataCorp).

\section{Patient and public involvement}

Patients and/or the public were not involved in the design, conduct, reporting or dissemination of this research.

\section{RESULTS}

A total of 3459 births with gestational age $>28$ weeks were born to 3278 pregnant women with obstetric emergencies arriving at one of the 24 public hospitals in Lagos state. The first babies of the 3278 women were included for analysis, of which 408 were stillbirths $(12.5 \%$ of all births). Of the stillbirths, 264 were described as fresh in the notes $(64.7 \%$ of stillbirths and $8.1 \%$ of all births), while 144 were described as macerated $(35.3 \%$ of stillbirths and $4.4 \%$ of all births). Women who experienced stillbirths were more likely to be in age group 20-34 years old $(67 \%)$, married $(96 \%)$, petty traders $(43 \%)$, multiparous $(73 \%)$, with singleton pregnancies $(91 \%)$, not registered for antenatal care (ANC) at the hospital in which the birth took place (unbooked) $(80 \%)$ and presented with bleeding as a complication (35\%). Stillbirths were also the most common among women who travelled directly from home to the hospital where they received care $(59 \%)$, during the week $(77 \%)$ and in the morning $(34 \%)$ as well as among women who were referred from primary healthcare centres $(38 \%)$ and had spontaneous vaginal birth $(56 \%)$ (table 1$)$. Women who had stillbirths travelled from inside and outside the state. For those within the state, most stillbirths originated from the city and suburb areas. A few stillbirths occurred among women who bypassed other public hospitals before reaching the facility of care with some needing to travel long distances to teaching hospitals in the central part of the state (figure 1).

A larger proportion of women who had fresh stillbirths travelled less than $10 \mathrm{~km}$ for delivery $(51 \%)$ with $47 \%$ of them getting to the facility of birth in less than 30 min. For women who had a macerated stillbirth, $65 \%$ of them travelled less than $10 \mathrm{~km}$ for delivery with $54 \%$ of them getting there in less than $30 \mathrm{~min}$ (table 2). Pregnant women travelled a median distance of $7.6 \mathrm{~km}$ (IQR 3.4-18.0) with a median time of 26 min (IQR 12-52). Women whose pregnancy resulted in a live birth travelled a median distance of $7.3 \mathrm{~km}$ (IQR 3.3-18.0) and a median time of 24 min (IQR 12-51). Those with stillbirths travelled a median distance of $8.5 \mathrm{~km}$ (IQR 4.4-19.7) and a median time of $30 \mathrm{~min}$ (IQR 16-60). Those whose pregnancy resulted in a fresh stillbirth travelled a median distance of $9.5 \mathrm{~km}$ (IQR 4.7-19.8) and used a median time of 32 min (IQR 18-56) to get to the facility of care. Women whose pregnancy resulted in a macerated stillbirth on the other hand travelled a median distance of $7.3 \mathrm{~km}$ (IQR 3.9-19.4) and got to the hospital in a median time of 27 min (IQR 14-60) (figure 2).

Age, employment status, parity, gestation, booking status, referral, type of referral facility, total distance and total time of travel were found to be significant factors from the bivariate analysis (table 3). When adjusted for sociodemographic, obstetric and pregnancy related factors (model I), the odds of pregnancy resulting in a stillbirth was significantly lower among women who were booked for ANC (OR 0.30, 95\% CI 0.23 to 0.39 ) and all women who presented with obstetric complications compared with women who presented with fetal complications (ranging from OR 0.09 (95\% CI 0.06 to 0.14 ) for obstructed labour to OR 0.31 (95\% CI 0.21 to 0.47 ) for haemorrhage and OR 0.32 (95\% CI 0.18 to 0.55 ) for sepsis). In addition, there was significantly lower odds of stillbirth for self-employed petty traders (OR 0.69, 95\% CI 0.52 to 0.93 ) and those who were employed (OR 0.66, $95 \%$ CI 0.46 to 0.95$)$. However, the odds of stillbirth were higher among women aged 35-50 years (OR 1.42, 95\% CI 1.10 to 1.84 ), with multiple gestation (OR 2.16, 95\% CI 1.41 to 3.29) and those who were referred (OR 1.42, $95 \%$ CI 1.12 to 1.81). When further adjusted for distance, all significant distance categories from the unadjusted model are lost (model II). When time of travel to facility was added (model III), the odds of stillbirth were seen to be significantly higher among women who got to a health facility for care between 10 and 29 min (OR 2.02, 95\% CI 1.30 to 3.13 ) and 30-59 $\min$ (OR $1.65,95 \%$ CI 1.03 to 2.63). The odds increased when distance and travel time were included in model IV, with significance evident for $10-29 \min$ (OR 2.25, 95\% CI 1.40 to 3.63), 30-59 $\min (\mathrm{OR}=2.30,95 \%$ CI 1.22 to 4.34$)$ and $60-119 \mathrm{~min}$ $(\mathrm{OR}=2.35,95 \%$ CI 1.05 to 5.25$)$ (table 4$)$.

In the subgroup analysis, the odds remained statistically significant for the 10-29 min in the non-referred group, but no significant association for total travel time in the referred group. For fresh stillbirths, statistical significance remained for 10-29 $\min$ (OR 2.19, 95\% CI 1.24 to 3.87 ) and 30-59 $\mathrm{min}$ (OR $2.13,95 \%$ CI 1.18 to 3.86 ). There was also statistical significance for $120-480 \mathrm{~min}$ (OR 2.41, 95\% CI 1.10 to 5.27). No statistical significance was found in any travel time category for macerated stillbirths (subgroup analyses in online supplemental tables $2-5)$.

\section{DISCUSSION}

In our study, we found that about two-thirds of women with macerated stillbirths travelled less than $10 \mathrm{~km}$ to the hospital with more than half requiring less than $30 \mathrm{~min}$ to travel. For women with fresh stillbirths, half of them 
Table 1 Sociodemographic, obstetric and travel-related characteristics of women with gestational age $>28$ weeks who gave birth in 1 of the 24 public hospitals in Lagos state $(\mathrm{N}=3278)$

\begin{tabular}{|c|c|c|c|}
\hline Characteristics & $\begin{array}{l}\text { No of pregnant } \\
\text { women }((\%) \mathrm{N}=3278)\end{array}$ & $\begin{array}{l}\text { No of stillbirths ((\%) } \\
\mathrm{n}=408)\end{array}$ & $\begin{array}{l}\text { No of live births } \\
((\%) n=2870)\end{array}$ \\
\hline \multicolumn{4}{|l|}{ Age } \\
\hline $12-19$ & $81(2.5)$ & $9(2.2)$ & $72(2.5)$ \\
\hline 20-34 & $2430(74.1)$ & $275(67.4)$ & 2155 (75.1) \\
\hline $35-50$ & 767 (23.4) & $124(30.4)$ & $643(22.4)$ \\
\hline \multicolumn{4}{|l|}{ Marital status } \\
\hline Single & $139(4.2)$ & $17(4.2)$ & $122(4.3)$ \\
\hline Married & 3139 (95.8) & $391(95.8)$ & $2748(95.7)$ \\
\hline \multicolumn{4}{|l|}{ Employment status } \\
\hline Unemployed/housewife & $563(17.2)$ & $86(21.1)$ & $477(16.6)$ \\
\hline Student & $166(5.1)$ & $17(4.2)$ & $149(5.2)$ \\
\hline Self-employed (petty-trader) & $1493(45.6)$ & $174(42.7)$ & $1319(46.0)$ \\
\hline Self-employed (mid-high business) & 357 (10.9) & $63(15.4)$ & $294(10.2)$ \\
\hline Employed & $699(21.3)$ & $68(16.7)$ & $631(22.0)$ \\
\hline \multicolumn{4}{|l|}{ Parity } \\
\hline Nulliparous (0) & $1127(34.4)$ & $109(26.7)$ & $1018(35.5)$ \\
\hline Multiparous (1-4) & $2071(63.2)$ & $284(69.6)$ & $1787(62.3)$ \\
\hline Grand-multiparous (5 or more) & $80(2.4)$ & $15(3.7)$ & $65(2.3)$ \\
\hline \multicolumn{4}{|l|}{ No of gestations } \\
\hline Singleton & $3112(94.9)$ & $373(91.4)$ & 2739 (95.4) \\
\hline Multiple & $166(5.1)$ & $35(8.6)$ & $131(4.6)$ \\
\hline \multicolumn{4}{|l|}{ Booking status } \\
\hline Booked & $1380(42.1)$ & $81(19.9)$ & $1299(45.3)$ \\
\hline Unbooked & $1898(57.9)$ & $327(80.1)$ & $1571(54.7)$ \\
\hline \multicolumn{4}{|l|}{ Fetal complications } \\
\hline No fetal complication & $2748(83.8)$ & $13(3.2)$ & 2735 (95.3) \\
\hline Reduced/absent fetal movement & $371(11.3)$ & $236(57.8)$ & $135(4.7)$ \\
\hline Intrauterine fetal death & $159(4.8)$ & $159(39.0)$ & $0(0.0)$ \\
\hline \multicolumn{4}{|l|}{ Obstetric complications } \\
\hline No maternal complication & $139(4.2)$ & $53(13.0)$ & $86(3.0)$ \\
\hline Obstructed labour & $990(30.2)$ & $51(12.5)$ & $939(32.7)$ \\
\hline Haemorrhage & $727(22.2)$ & $144(35.3)$ & $583(20.3)$ \\
\hline Pre-eclampsia/eclampsia & $923(28.2)$ & $96(23.5)$ & $827(28.8)$ \\
\hline Sepsis & $169(5.2)$ & $29(7.1)$ & $140(4.9)$ \\
\hline Others & $330(10.1)$ & $35(8.6)$ & $295(10.3)$ \\
\hline \multicolumn{4}{|l|}{ Weekend travel to facility } \\
\hline Yes & 751 (22.9) & $92(22.6)$ & $659(23.0)$ \\
\hline No & $2527(77.1)$ & $316(77.4)$ & $2211(77.0)$ \\
\hline \multicolumn{4}{|c|}{ Period of day of travel to the facility $(n=2187)$} \\
\hline Morning & 801 (36.6) & $90(34.4)$ & 711 (36.9) \\
\hline Afternoon & $582(26.6)$ & 67 (25.6) & $515(26.8)$ \\
\hline Evening & 501 (22.9) & $56(21.4)$ & 445 (23.1) \\
\hline Night & 303 (13.9) & $49(18.7)$ & 254 (13.2) \\
\hline Referral & & & \\
\hline
\end{tabular}


Table 1 Continued

\begin{tabular}{|c|c|c|c|}
\hline Characteristics & $\begin{array}{l}\text { No of pregnant } \\
\text { women }((\%) \mathrm{N}=3278)\end{array}$ & $\begin{array}{l}\text { No of stillbirths ((\%) } \\
n=408)\end{array}$ & $\begin{array}{l}\text { No of live births } \\
((\%) n=2870)\end{array}$ \\
\hline Not referred & $2384(72.7)$ & $242(59.3)$ & $2142(74.6)$ \\
\hline Referred & $894(27.3)$ & $166(40.7)$ & $728(25.4)$ \\
\hline \multicolumn{4}{|l|}{ Referral facility $(n=894)$} \\
\hline Another hospital (public) & $141(15.8)$ & $24(14.4)$ & $117(16.1)$ \\
\hline Another hospital (private & $179(20.0)$ & $42(25.2)$ & $137(18.8)$ \\
\hline Clinic (public or private) & $66(7.4)$ & $3(1.8)$ & $63(8.7)$ \\
\hline Primary health centre & $390(43.6)$ & $64(38.3)$ & $326(44.8)$ \\
\hline Traditional birth attendant & $92(10.3)$ & $27(16.2)$ & $65(8.9)$ \\
\hline Nursing/maternity home & $6(0.7)$ & $2(1.2)$ & $4(0.6)$ \\
\hline Non-formal referral (Church or Mosque) & $20(2.2)$ & $5(3.0)$ & $15(2.1)$ \\
\hline \multicolumn{4}{|l|}{ Mode of birth } \\
\hline Spontaneous vaginal birth & $1211(36.9)$ & $230(56.4)$ & 981 (34.2) \\
\hline Assisted vaginal birth & $144(4.4)$ & $23(5.6)$ & $121(4.2)$ \\
\hline Caesarean birth & 1923 (58.7) & $155(38.0)$ & 1768 (61.6) \\
\hline
\end{tabular}

travelled less than $10 \mathrm{~km}$ to the hospital and more than half required less than $30 \mathrm{~min}$ to reach the hospital of care. This finding of high proportions of poor outcomes for babies born to women travelling within $10 \mathrm{~km}$ and under half an hour to a hospital has been reported in other studies that explored association between neonatal outcomes and travel time or distance. In Nigeria, more than $75 \%$ of mothers with stillbirths travelled within 30 min to the hospital of care, ${ }^{14}$ and in Malawi and Zambia, $84 \%$ and $67 \%$ of mothers, respectively, travelled within $10 \mathrm{~km} .{ }^{12}$ In Rwanda, of women who reached a health centre, almost $45 \%$ of them still travelled an additional 30-60 min to the hospital requiring caesarean section. ${ }^{13}$
Aggregating travel time, we estimated a median travel time of 26 min (IQR 12-52) for all women with traceable journeys. This was significantly lower than the $60 \mathrm{~min}$ median travel time self-reported by over 1000 women who had an emergency caesarean birth in nine hospitals in Sierra Leone. ${ }^{11}$ Evidence shows that estimates using Google Maps, like we have done in our study, are more reflective of reality compared with models. ${ }^{26}$ On the other hand, self-reported travel time are usually higher than modelled estimates. ${ }^{11}$ While, methodological differences may explain the difference, it might also relate with road transport quality. Benchmarking with South Africa as highest quality (100), road transport quality index in

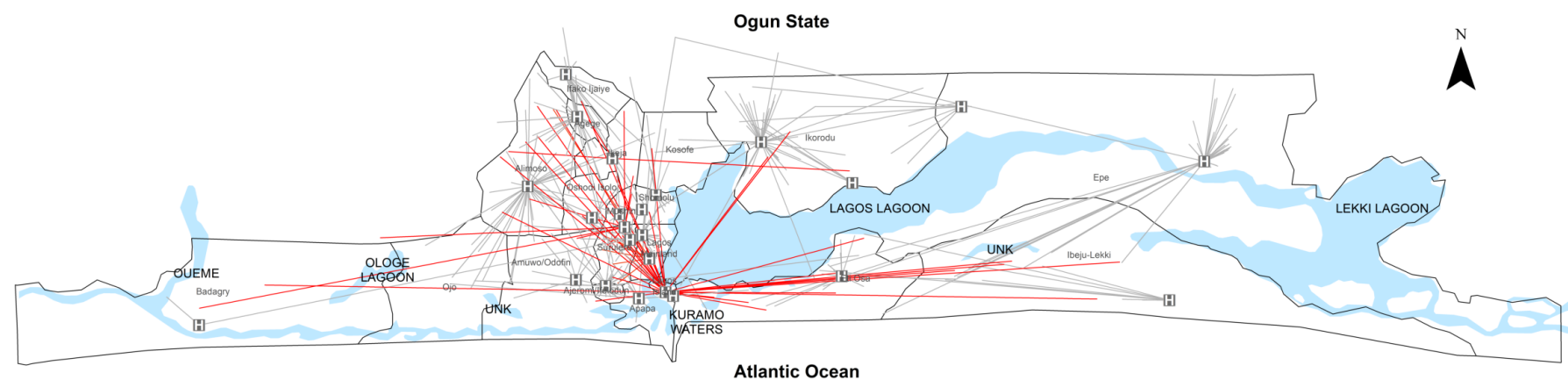

Atlantic Ocean

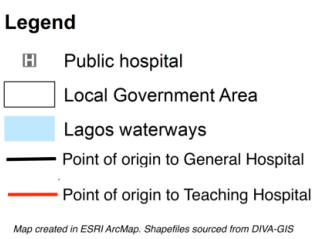

Figure 1 Map of Lagos showing points of origin of women with stillbirths in relation to Lagos public hospitals. Black lines link point of origin of women who had stillbirths in Lagos during to study period to the general hospital where they received care. Red lines link point of origin of women who had stillbirths in Lagos during to study period to the teaching hospital where they received care. 
Table 2 Description of distance and time to facility by fetal outcome $(\mathrm{N}=2797)^{\star}$ for women who had traceable journeys to care

\begin{tabular}{|c|c|c|c|c|}
\hline \multirow[t]{2}{*}{ Characteristics } & \multirow[t]{2}{*}{ Total (n (\%)) } & \multicolumn{2}{|l|}{ Stillbirth (n (\%)) } & \multirow[t]{2}{*}{ Live birth (n (\%)) } \\
\hline & & Fresh stillbirth (n (\%)) & Macerated stillbirth (n (\%)) & \\
\hline \multicolumn{5}{|c|}{ Total distance for all women whose journeys were traceable $\left(\mathrm{N}=2797^{*}\right)$} \\
\hline Within $5 \mathrm{~km}$ & $1051(37.6)$ & $53(26.8)$ & $45(37.0)$ & $953(38.5)$ \\
\hline $5-10 \mathrm{~km}$ & $621(22.2)$ & $48(24.2)$ & $34(27.9)$ & $539(21.8)$ \\
\hline$>10-15 \mathrm{~km}$ & $304(10.9)$ & $26(13.1)$ & $8(6.6)$ & $270(10.9)$ \\
\hline$>15-20 \mathrm{~km}$ & $194(6.9)$ & $25(12.6)$ & $5(4.1)$ & $164(6.6)$ \\
\hline$>20-25 \mathrm{~km}$ & $146(5.2)$ & $12(6.1)$ & $3(2.5)$ & $131(5.3)$ \\
\hline$>25-30 \mathrm{~km}$ & $121(4.3)$ & $4(2.0)$ & $7(5.7)$ & $110(4.4)$ \\
\hline$>30-35 \mathrm{~km}$ & $85(3.0)$ & $6(3.0)$ & $2(1.6)$ & $77(3.1)$ \\
\hline$>35 \mathrm{~km}$ & $275(9.8)$ & $24(12.1)$ & $18(14.7)$ & $233(9.4)$ \\
\hline \multicolumn{5}{|c|}{ Total time for all women whose journeys were traceable $\left(\mathrm{N}=2797^{\star}\right)$} \\
\hline $0-9 \min$ & $513(18.3)$ & $16(8.1)$ & $13(10.7)$ & $484(19.5)$ \\
\hline $10-29 \min$ & $1020(36.5)$ & 76 (38.4) & $53(43.4)$ & $891(36.0)$ \\
\hline 30-59 min & 652 (23.3) & 58 (29.3) & 23 (18.9) & $571(23.1)$ \\
\hline $60-119 \mathrm{~min}$ & 484 (17.3) & 32 (16.2) & $27(22.1)$ & 425 (17.2) \\
\hline $120-480 \mathrm{~min}$ & $128(4.6)$ & $16(8.1)$ & $6(4.9)$ & 106 (4.3) \\
\hline
\end{tabular}

${ }^{*}$ Excludes pregnant women whose journey to the facility could not be determined $(n=481)$.

Nigeria (32.3) is two and a half times better compared with Sierra Leone (9.6). ${ }^{30}$ When disaggregated by pregnancy outcome, we found that pregnant women with a live birth had a lower median travel time (24 min (IQR 12-51)) compared with those with fresh (32 min (IQR 18-56) or macerated stillbirths (27 min (IQR 14-60)). Longer travel time among stillbirths compared with live births is in line with expected consequences of phase II delays as per Thaddeus and Maine's framework. ${ }^{8}$ Intuitively, we also expected macerated stillbirths would have required longer travel times to reach the hospital being that these occur antepartum and not while the woman is in labour when there would have been more urgency to travel. However, we found the contrary. It could be that the delay with many of the macerated stillbirths occurred even before the pregnant women commenced their journeys to the hospital (phase I). We are not able to ascertain this based on the data captured in our study. Assessing the mean estimates of travel time, we find that these were consistently higher than the median estimates in our study, showing that our distribution is positively skewed. As per our quick systematic search of the literature, we found only one other study that reported mean travel time, and this was conducted in Gombe city, northeastern part of Nigeria. Based on modelling, the authors in that study reported a mean travel time of about 15 and 26 min for women with live and stillbirths, respectively. ${ }^{14}$ Again, while difference in time estimation methods may explain some of the observed difference, our 38, 43 and 48 min estimated for livebirths, macerated and fresh stillbirths may be a pointer to the more urbanised nature of Lagos compared with Gombe. This urbanised nature comes with concomitant traffic in commuting. ${ }^{31}$

In aggregating distance, we found a median distance to the hospital of care of $7.6 \mathrm{~km}$ (IQR 3.4-18.0) in our study. We found no other study that reported median distances to the hospital of care for stillbirths or perinatal deaths. As such, we were unable to make any comparisons. However, like travel time, distribution was positively skewed with mean distance of travel almost twice of the median for all births.

Our study showed that after adjusting for confounders, there was a progressively increasing likelihood of stillbirth as pregnant women with obstetric emergencies needed to travel for longer time to a hospital that can provide the care that they and their unborn child required. As our findings show, by the time a woman is needing to travel for more than 2 hours to reach a hospital that can provide care, there is an almost two and a half times higher odds of that pregnancy resulting in a stillbirth. A recent study in a referral hospital located in a north-eastern city of Nigeria showed that women who lived more than $60 \mathrm{~min}$ from the referral hospital were 12 times more likely of having a stillborn compared with those who lived within 15 min of travel to the referral hospital. ${ }^{14}$ In our study, we found that the odds for stillbirth doubled even for journeys that took between 10 and $29 \mathrm{~min}$. Though a high-income setting, a study in the Netherlands found $17 \%$ higher odds for journeys more than $20 \mathrm{~min}$ to a facility of care. ${ }^{32}$ The relatively more urban nature of Lagos compared with Gombe city and the fact that that study only focused on one referral hospital and the more 


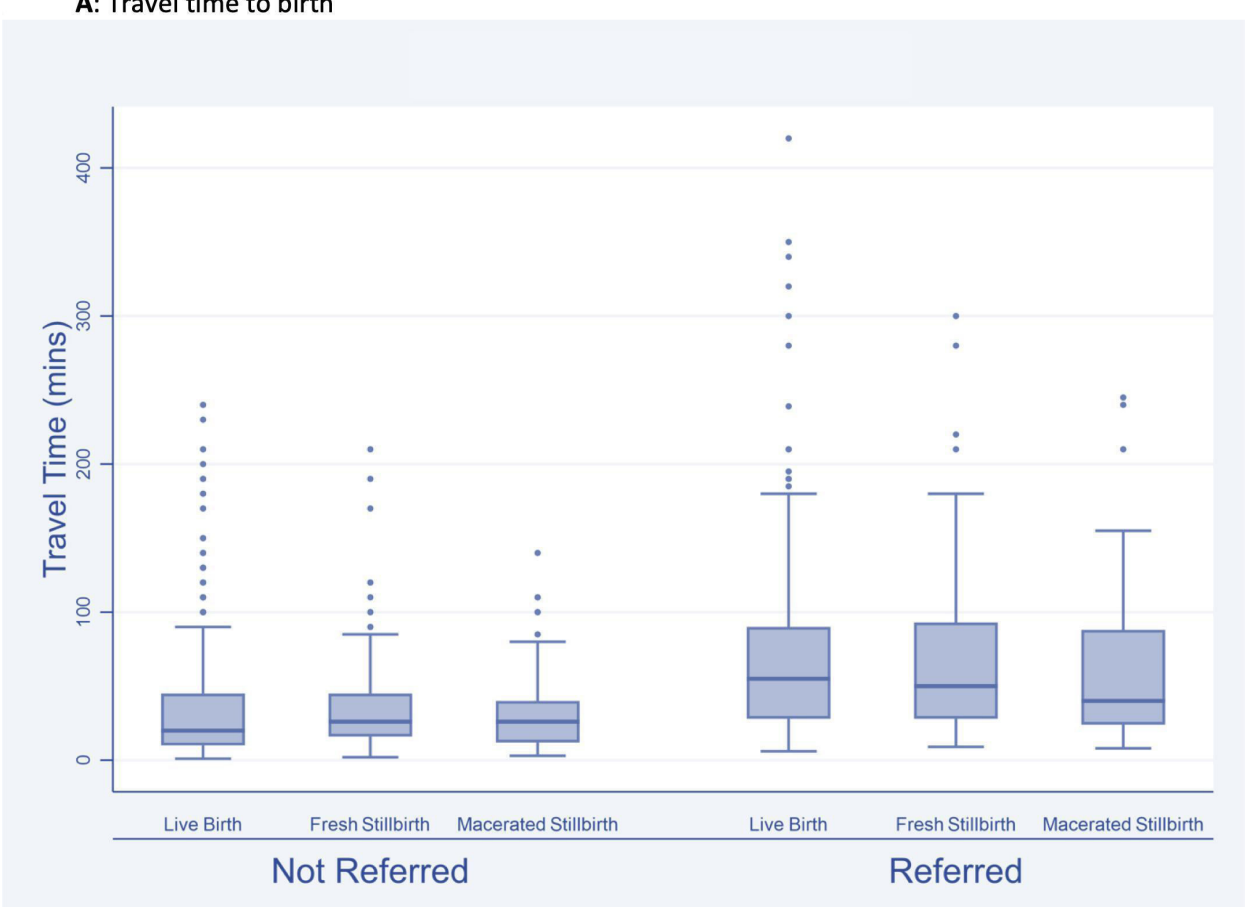

B: Distance to birth

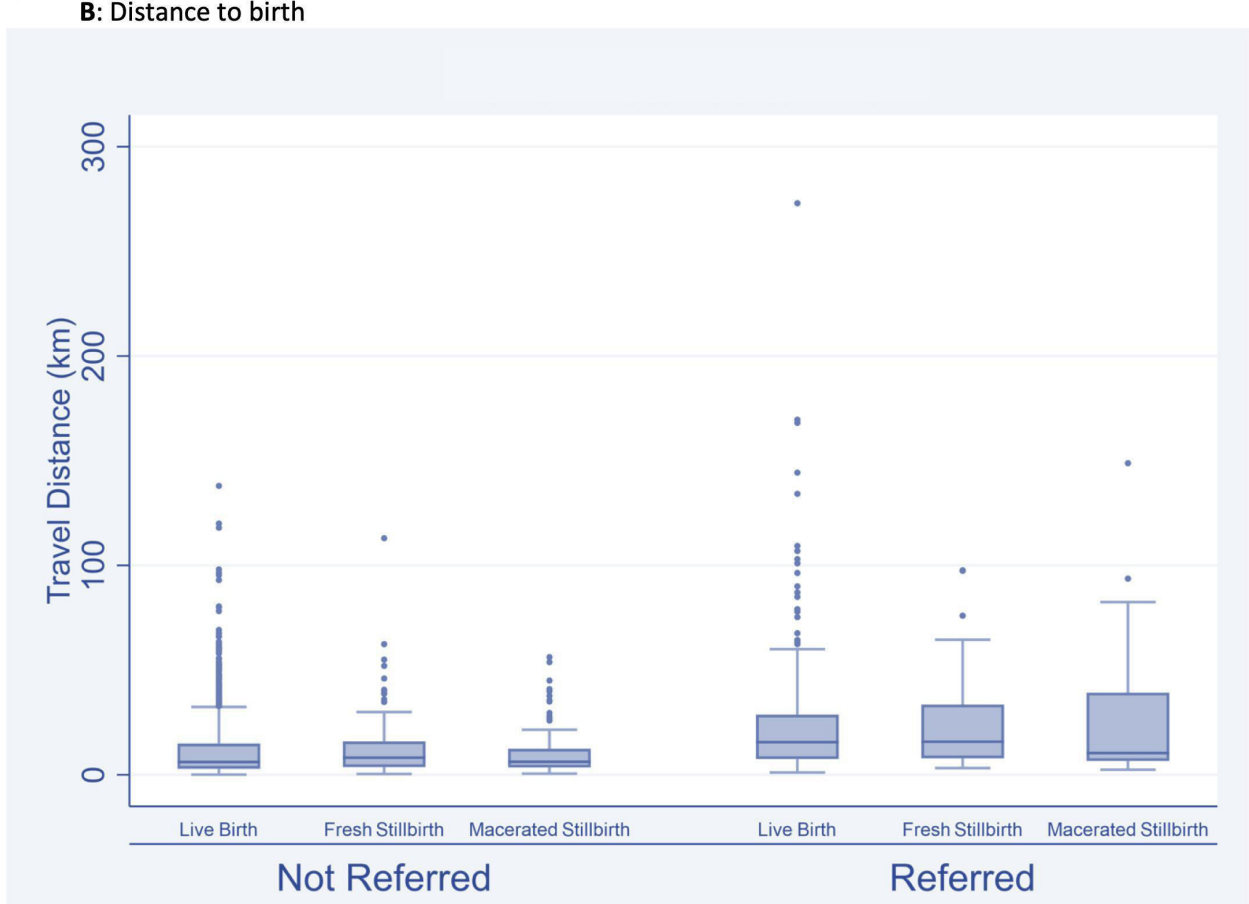

Figure 2 Box and whisker plot of distance and time to the hospital of care by category of stillbirth and referral status. Excludes pregnant women whose journey to facility could not be determined $(n=481)$.

developed setting in the Netherlands might explain the discrepancy in the odds. However, clearly, there is an emerging pattern. Our subgroup analyses showing that the significant association remained when fresh stillbirths, which occur after the onset of labour, are specifically identified, strengthens the evidence base relating to the influence of travel time on stillbirths.
For distance, while we found increased odds for stillbirths in our unadjusted model, after adjusting for confounders, our adjusted model showed no significant association between distance and stillbirth. Though no specific study has looked at distance to care and stillbirth, a similar study looked at distance to care and early neonatal mortality. The authors found a non-significant 
Table 3 Bivariate analysis for fetal outcomes ( $\mathrm{N}=3278)$

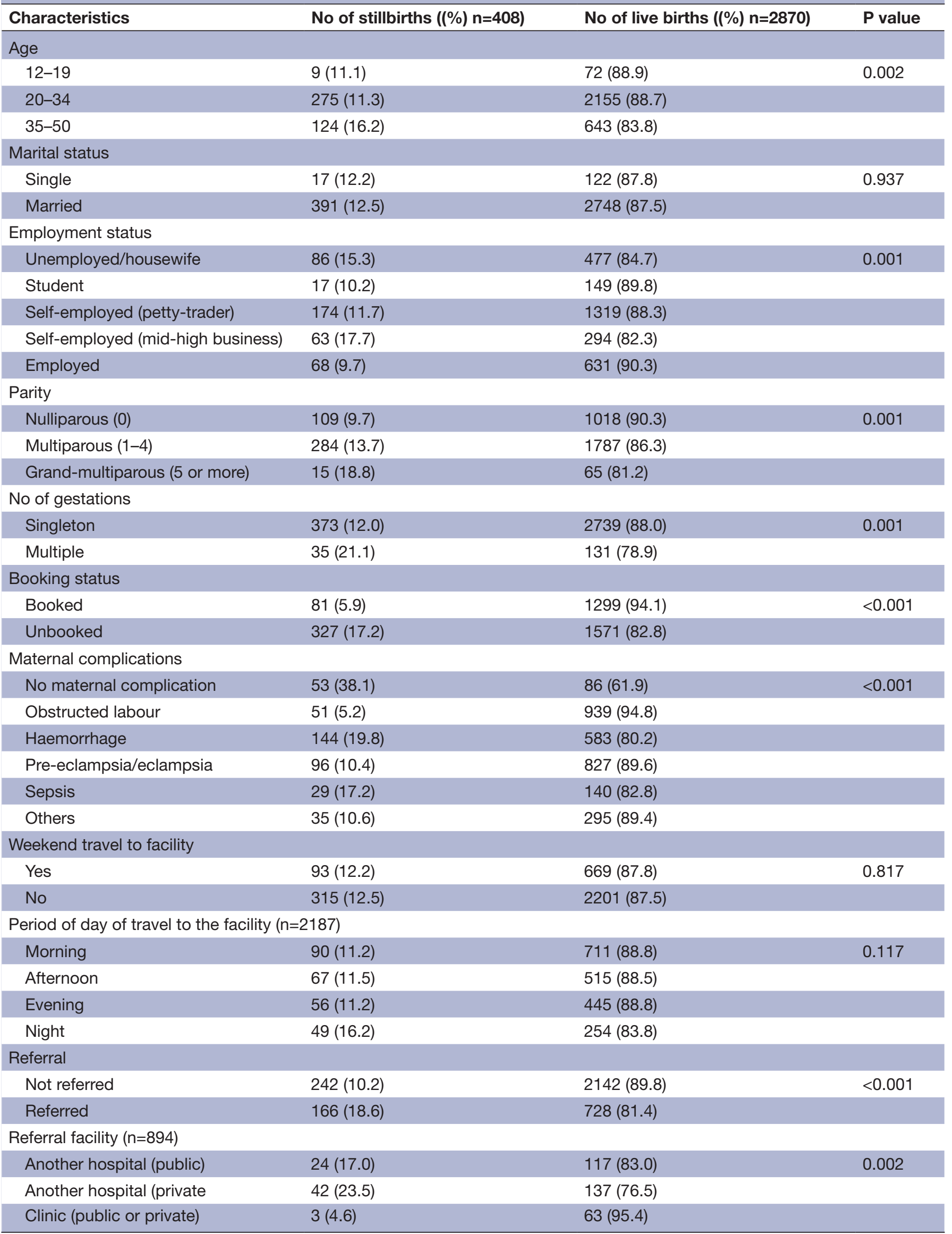


BMJ Global Health

\begin{tabular}{|c|c|c|c|}
\hline Characteristics & No of stillbirths $((\%) n=408)$ & No of live births ((\%) n=2870) & $P$ value \\
\hline Primary health centre & $64(16.4)$ & $326(83.6)$ & \\
\hline Traditional birth attendant & $27(29.4)$ & $65(70.6)$ & \\
\hline Nursing/maternity home & $2(33.3)$ & $4(66.7)$ & \\
\hline Non-formal referral & $5(25.0)$ & $15(75.0)$ & \\
\hline \multicolumn{4}{|c|}{ Distance of travel from home directly to a hospital $(n=2259 \ddagger)$} \\
\hline Within $5 \mathrm{~km}$ & $83(8.6)$ & $885(91.4)$ & 0.057 \\
\hline $5-10 \mathrm{~km}$ & $63(12.4)$ & $447(87.6)$ & \\
\hline$>10-15 \mathrm{~km}$ & $19(8.0)$ & $220(92.0)$ & \\
\hline$>15-20 \mathrm{~km}$ & $21(15.3)$ & $116(84.7)$ & \\
\hline$>20-25 \mathrm{~km}$ & $8(8.9)$ & $82(91.1)$ & \\
\hline$>25-30 \mathrm{~km}$ & $9(10.1)$ & $80(89.9)$ & \\
\hline$>30-35 \mathrm{~km}$ & $2(3.5)$ & $55(96.5)$ & \\
\hline$>35 \mathrm{~km}$ & $17(10.1)$ & $152(89.9)$ & \\
\hline \multicolumn{4}{|c|}{ Distance of travel from home to initial facility for referred women $(n=538 \dagger)$} \\
\hline Within $5 \mathrm{~km}$ & $47(18.7)$ & $205(81.3)$ & 0.513 \\
\hline $5-10 \mathrm{~km}$ & $16(14.9)$ & $91(85.1)$ & \\
\hline$>10-15 \mathrm{~km}$ & $12(20.7)$ & $46(79.3)$ & \\
\hline$>15-20 \mathrm{~km}$ & $9(21.9)$ & $32(78.1)$ & \\
\hline$>20-25 \mathrm{~km}$ & $3(10.7)$ & $25(89.3)$ & \\
\hline$>25-30 \mathrm{~km}$ & $2(11.1)$ & $16(88.9)$ & \\
\hline$>30-35 \mathrm{~km}$ & $3(42.9)$ & $4(57.1)$ & \\
\hline$>35 \mathrm{~km}$ & $6(22.2)$ & $21(77.8)$ & \\
\hline \multicolumn{4}{|c|}{ Distance of travel from initial facility to final facility of care for referred women $(n=538 \dagger)$} \\
\hline Within $5 \mathrm{~km}$ & $37(18.5)$ & $163(81.5)$ & 0.408 \\
\hline $5-10 \mathrm{~km}$ & $18(14.5)$ & $106(85.5)$ & \\
\hline$>10-15 \mathrm{~km}$ & $11(17.2)$ & $53(82.8)$ & \\
\hline$>15-20 \mathrm{~km}$ & $11(22.0)$ & $39(78.0)$ & \\
\hline$>20-25 \mathrm{~km}$ & $4(12.5)$ & $28(87.5)$ & \\
\hline$>25-30 \mathrm{~km}$ & $3(14.3)$ & $18(85.7)$ & \\
\hline$>30-35 \mathrm{~km}$ & $3(37.5)$ & $5(62.5)$ & \\
\hline$>35 \mathrm{~km}$ & $11(28.2)$ & $28(71.8)$ & \\
\hline \multicolumn{4}{|c|}{ Total traceable distance for all women whose journeys were traceable $\left(n=2797^{*}\right)$} \\
\hline Within $5 \mathrm{~km}$ & $98(9.3)$ & $953(90.7)$ & 0.038 \\
\hline $5-10 \mathrm{~km}$ & $82(13.2)$ & $539(86.8)$ & \\
\hline$>10-15$ km & $34(11.2)$ & $270(88.8)$ & \\
\hline$>15-20 \mathrm{~km}$ & $30(15.5)$ & $164(84.5)$ & \\
\hline$>20-25 \mathrm{~km}$ & $15(10.3)$ & $131(89.7)$ & \\
\hline$>25-30 \mathrm{~km}$ & $11(9.1)$ & $110(90.9)$ & \\
\hline$>30-35$ km & $8(9.4)$ & $77(90.6)$ & \\
\hline$>35 \mathrm{~km}$ & $42(15.3)$ & $233(84.7)$ & \\
\hline \multicolumn{4}{|c|}{ Time of travel from home directly to a hospital ( $N=2259 \ddagger)$} \\
\hline $0-9 \min$ & $27(5.5)$ & $464(94.5)$ & 0.009 \\
\hline 10-29 min & $102(11.4)$ & $794(88.6)$ & \\
\hline $30-59 \min$ & $54(10.8)$ & $447(89.2)$ & \\
\hline $60-119 \min$ & $33(10.4)$ & $284(89.6)$ & \\
\hline
\end{tabular}


Table 3 Continued

\begin{tabular}{|c|c|c|c|}
\hline Characteristics & No of stillbirths $((\%) n=408)$ & No of live births $((\%) n=2870)$ & P value \\
\hline $120-480 \mathrm{~min}$ & $6(11.1)$ & $48(88.9)$ & \\
\hline \multicolumn{4}{|c|}{ Time of travel from home to initial facility for referred women $(n=538 \dagger)$} \\
\hline $0-9 \min$ & $24(20.2)$ & $95(79.8)$ & 0.116 \\
\hline 10-29 min & $39(18.8)$ & $168(81.2)$ & \\
\hline 30-59 min & $19(14.7)$ & $110(85.3)$ & \\
\hline $60-119 \mathrm{~min}$ & $9(13.8)$ & $56(86.2)$ & \\
\hline $120-480 \mathrm{~min}$ & $7(38.9)$ & $11(61.1)$ & \\
\hline \multicolumn{4}{|c|}{ Time of travel from initial facility to final facility of care for referred women $(n=538+)$} \\
\hline $0-9 \min$ & 16 (15.7) & 86 (84.3) & 0.275 \\
\hline $10-29 \mathrm{~min}$ & $39(20.0)$ & $156(80.0)$ & \\
\hline 30-59 min & $20(13.8)$ & 125 (86.2) & \\
\hline $60-119 \mathrm{~min}$ & 19 (23.2) & $63(76.8)$ & \\
\hline $120-480 \mathrm{~min}$ & $4(28.6)$ & $10(71.4)$ & \\
\hline \multicolumn{4}{|c|}{ Total travel time for all women whose journeys were traceable $(n=2797 \dagger)$} \\
\hline $0-9 \min$ & $29(5.7)$ & 484 (94.3) & $<0.001$ \\
\hline $10-29 \mathrm{~min}$ & $129(12.7)$ & 891 (87.3) & \\
\hline 30-59 min & $81(12.4)$ & $571(87.6)$ & \\
\hline $60-119 \min$ & 59 (12.2) & 425 (87.8) & \\
\hline $120-480 \mathrm{~min}$ & 22 (17.2) & 106 (82.8) & \\
\hline
\end{tabular}

Mode of birth was excluded from the bivariate analysis, as the outcome occurred before the birth.

*Excludes women whose journey from home to health facility could not be determined $(n=125)$.

$\dagger$ Excludes women whose referral journey could not be determined $(n=356)$.

$\ddagger$ Excludes women whose journey to facility could not be determined $(n=134)$.

relationship in Malawi but found that every additional $10 \mathrm{~km}$ distance was associated with lower early neonatal mortality in Zambia. ${ }^{12}$ This study only included rural births, as defined by the Demographic and Health Surveys of both countries. ${ }^{12}$ In our study, the explanation for the non-significance requires consideration for some of the other variables captured in our research. All evidence points to the higher risk of a stillbirth occurring compared with a maternal death when there is any form of obstetric compromise, and indeed stillbirths occur more commonly than maternal deaths. ${ }^{133}$ A deeper dive into our study findings shows that babies of women who had 'perceivable' complications like obstructed labour or haemorrhage had lower odds of dying compared with babies whose mothers had no obstetric complication of their own and only reported in the emergency because of concerns they had for their babies. We argue that the reason for non-significance for distance relates to the fact that women with 'perceivable' obstetric complication do not start their journeys early. As such, it really does not matter how far they need to travel (distance), by the time they set out, the risk for obstetric compromise for the newborn is established. This argument is supported by other evidence that risk perception has an influence on when and how soon pregnant women travel to reach a health facility in situations of emergency. ${ }^{9}$
Another significant factor of being booked for ANC has also been reported as being associated with reduced odds of stillbirth in hospitals in another study. ${ }^{21}$ Booking allows skilled personnel to promptly identify potential risky pregnancies. On the other hand, being referred and having multiple gestations have been associated with significantly higher odds of stillbirth in hospitals. ${ }^{21}$ The explanation for both probably relates with high-risk nature of the multiple gestations and any pregnancy that requires a referral. Our finding of significantly lower odds of stillbirths among self-employed petty traders and employed women probably relates to these women being relatively educated or having the means to live in more developed parts of the states that will have the hospitals close by. However, this needs to be further explored.

Our study has some key strengths worth highlighting. First, to the best of our knowledge, it is the first study conducted in an LMIC setting that explicitly and comprehensively explored association between travel time, distance and stillbirths. The study used estimates of distance and travel time from Google Maps, which are closer to reality. ${ }^{26}$ However, our study also has some limitations that should be considered in interpreting our findings. First, we used reported clinical data, as such, there are some data that are not routinely recorded in patient notes and others not properly recorded. Indeed, 


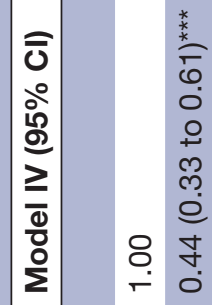

ธิ

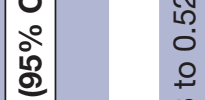

三

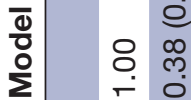

당

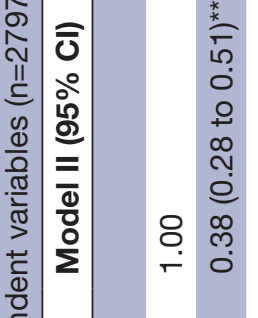

$\frac{8}{80}$

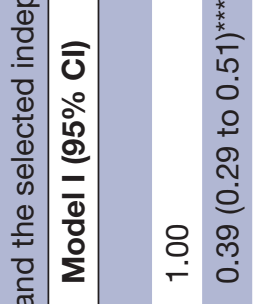

단

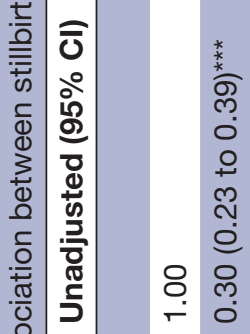

盖盖考盖恶

$\circ 0$ 0 00

우아 우우우

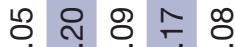

¿ 0 อ

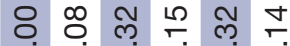

- वं व लं

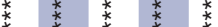

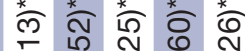

$\circ \circ 000$

우웅ㅇㅇㅇㅇㅛ

원든 수

อ อ 巳

吕串

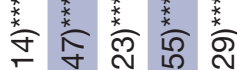

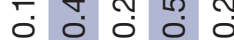

우아 웅ㅇㅇㅜ

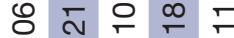

¿ อ อ อ

8 व ल

- Oे O O O

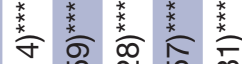

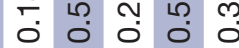

웅ㅇㅇㅇㅇㅇㅇ

\& N

¿ 巳 巳 巳 巳

88 웅
员

$\begin{array}{llll}0 & 0 & 0 & 0 \\ 0 & 0 & 0\end{array}$

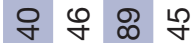

อ อ อ

욱 융

- 0 ○

ส

$\begin{array}{rrrr}1 & 0 & 0 \\ 0 & 0 & 0 & 0 \\ 0 & 0 & 0\end{array}$

敌众年

อ 0 อ

운

\begin{abstract}
००
\end{abstract}

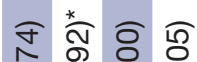

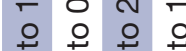

f

อ อ อ

움 융

.

बृ

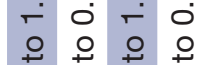

品

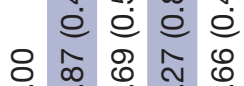

웅

类

m

t?

赵

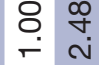

仓̊ํํㅇ

융유

बำ

ํ.

ก

$\therefore$.

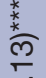

+்

$\circ$

8

in

盖

$\stackrel{m}{\circ}$

它

$8 \div$

ล

움 ๆ

$\circ \%$

당

จิ ลำ

.

요우

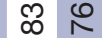

$\stackrel{\infty}{0}$

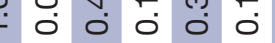

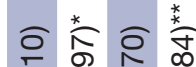

- 0 -

우옹ㅇㅇ

8 ஜ
郘

อ 巳 巳 อ
:

i

웅

ल)

$\stackrel{2}{\circ}$

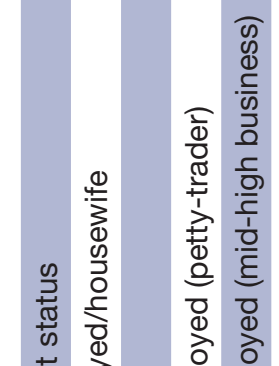

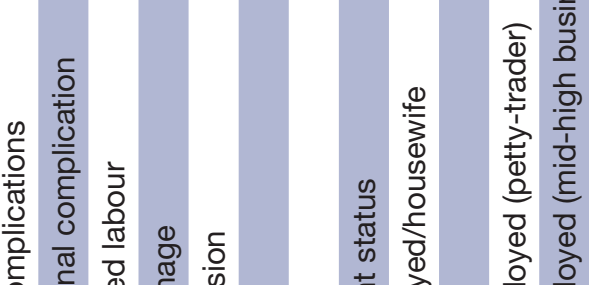

क

\section{.}

+.

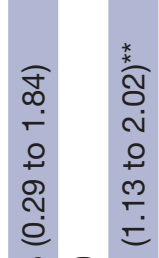

ल 8 in

o

$\circ$

움

๙্ষ

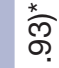

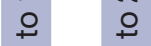

ल

¿

송 \&

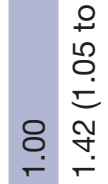

$\overrightarrow{0}$

$\vec{\omega}$

음.

谂

के̀े

웅

용

苛

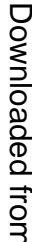

言

을

$\frac{\sigma}{3}$

ஓ

옥

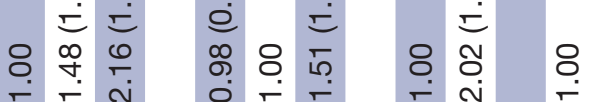

을.

뜬

N

N

잉

$\rightarrow$

$\frac{0}{\overline{0}}$

용

ত্

흘 

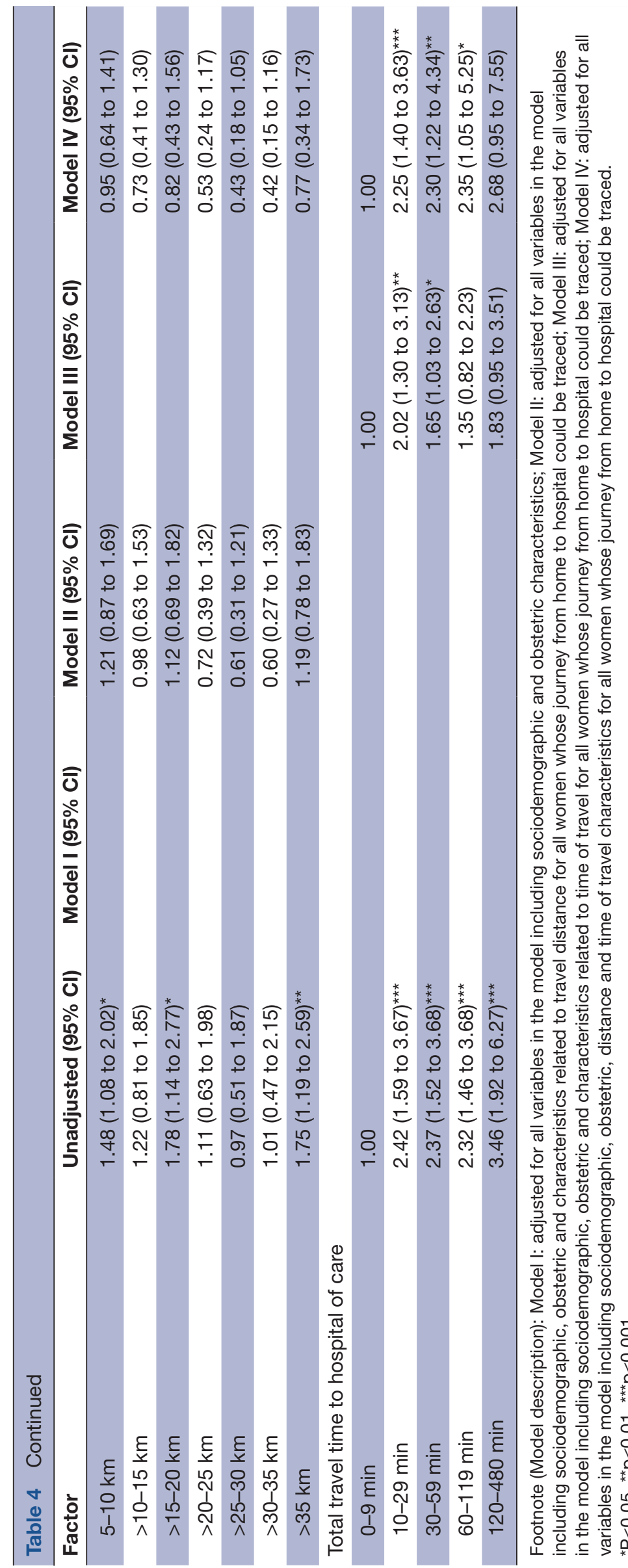

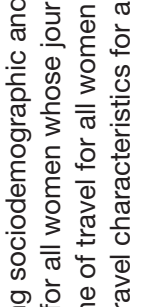

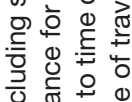

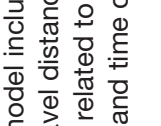

ह

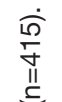

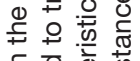

$\subseteq$ D $\frac{\Phi}{0 .}$

ब

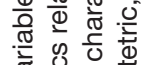

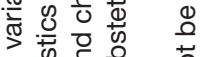

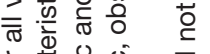

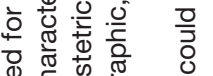

年

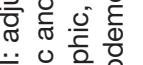

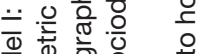

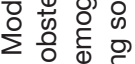

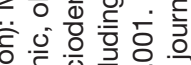

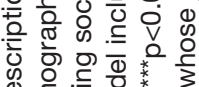

क्षे है

응 응요

$\sum$ o d ․․‥

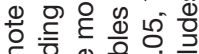

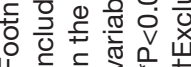


our analysis of such secondary data is only as good as the data that was originally collected. Completeness and accuracy of the original data could have influenced our classification of stillbirths and traceability of journeys taken by the women. In addition, we have mapped journeys based on reported locations in the case notes. However, we do not know for a fact that this is truly the path that women followed. Furthermore, though we captured travel over the period of a year and accounted for diurnal variations, our estimation of travel time using Google Maps did not account for any seasonal variations in road conditions due to flooding during the wet season and other events that may lead to travel delays in certain periods of the year. This could not be done as the Google Maps typical time of travel tool does not currently have the functionality of estimating varied travel time for different seasons. Finally, in estimating travel time, we have not included time to find a vehicle before travelling, nor have we considered time spent in deciding to seek care and in attempts made by skilled and unskilled personnel in providing care in an initial facility for those who were subsequently referred. ${ }^{9}$ Indeed, hospital records do not typically have sufficient data to comprehensively and accurately understand time spent in both phases. ${ }^{34}$ Also, for women who are referred, they are experiencing the third delay potentially more than once, not just in the final hospital but also in the intermediate facilities. This is difficult to assess unless the research is conducted is some prospective manner allowing researchers to follow each woman on her journey. Our study was retrospectively conducted. In any case, while this could have helped with better understanding of the influence of delays across the three phases, our focus was primarily on travel time. The same approach of estimating just travel time has been used in other studies. ${ }^{1114}$

Future research should consider a prospective approach to this study, as it will address some of the limitations around accounting for seasonality and the time contribution of other phases to pregnancy outcomes. There is also a case for exploring the potential for minimising risk of stillbirths if women who had stillbirths had used nearer and functional hospitals. In addition, there are some implications for policy and practice emanating from our study findings. First, a high number of stillbirths still occur among women who make it to a hospital with over a third of all stillbirths being macerated. Indeed, before pregnant women need to travel, being booked for ANC remains essential for optimising pregnancy outcomes for them and their babies. Skilled health personnel should use ANC visits to discuss travel plans with couples as part of birth preparedness. It is also important to keep in mind that out of preference or not appreciating the urgency, some pregnant women might choose to bypass services. ${ }^{92-24}$ As our study shows that time is critical for newborn survival, ANC visits of mothers should also be used to discuss recognition of signs of potential compromise as well as hospitals they can if they feel there might be an issue with their babies. Schemes that support women to arrive at facilities in quick time or can start providing the care needed before she arrives at the hospital should be considered. Both can be addressed by providing fully equipped $24 / 7$ ambulances at no-cost to women, which led to some reduction in stillbirths in Uganda. ${ }^{35}$ However, for this to work, particularly in principally urban LMIC settings like Lagos, issues that limit effectiveness of ambulances, such as commuters' unwillingness to give way to ambulances, ${ }^{9}$ need to be addressed. In addition, governments need to really ensure that hospitals with full capacity to provide EmOC are in sites where they can be easily accessed, ${ }^{36}{ }^{37}$ while investing in strengthening of referral systems.

\section{CONCLUSION}

Travel time to a hospital that can provide the care needed by pregnant women or their babies with obstetric emergencies was strongly associated with stillbirth. While birth preparedness incorporated in routine ANC and counselling to use contraception to minimise number of pregnancies can significantly reduce odds of stillbirths, amid the crisis, efforts to get quality care in quicker time to women or women quicker to quality care will be critical for efforts to reduce stillbirths in high burden countries like Nigeria.

Twitter Aduragbemi Banke-Thomas @abankethomas, Cephas Ke-on Avoka @AvokaKeon and Lenka Benova @lenkabenova

Acknowledgements We are grateful to the Lagos State Government, in particular, the Lagos State Ministry of Health and the Lagos State Health Service Commission, for their support in gaining access to all state-owned facilities. We also thank the leadership of Federal government-owned facilities (Federal Medical Centre Ebute-Metta and Lagos University Teaching Hospital) included in our study for their support. We are indebted to the medical officers and residents who helped with collating case notes of pregnant women to be included in the study. We also thank the AXA Research Fund for supporting this research.

Contributors $A B-T$ conceived the study and wrote the protocol. AB-T, CK-OA and $\mathrm{LB}$ designed the study. $\mathrm{AB}-\mathrm{T}$ led data collection. $\mathrm{AB}-\mathrm{T}$ and $\mathrm{CK}-\mathrm{OA}$ did the statistical analyses. AB-T, UG-A and CK-OA wrote the first draft of the article. All authors critically reviewed the article, contributed to the interpretation of findings, saw and approved the final version of the article.

Funding This research was funded by grant provided by AXA Research Fund. Competing interests None declared.

\section{Patient consent for publication Not applicable.}

Ethics approval The study was approved by the Research and Ethics Committees of the Lagos State University Teaching Hospital (LREC/06/10/1226) and Lagos University Teaching Hospital (ADM/DCST/HREC/APP/2880). Social approval was obtained from the Lagos State Government (LSHSC/2222/NOLII/107).

Provenance and peer review Not commissioned; externally peer reviewed.

Data availability statement Data are available on reasonable request.

Supplemental material This content has been supplied by the author(s). It has not been vetted by BMJ Publishing Group Limited (BMJ) and may not have been peer-reviewed. Any opinions or recommendations discussed are solely those of the author(s) and are not endorsed by BMJ. BMJ disclaims all liability and responsibility arising from any reliance placed on the content. Where the content includes any translated material, BMJ does not warrant the accuracy and reliability of the translations (including but not limited to local regulations, clinical guidelines, terminology, drug names and drug dosages), and is not responsible for any error and/or omissions arising from translation and adaptation or otherwise.

Open access This is an open access article distributed in accordance with the Creative Commons Attribution Non Commercial (CC BY-NC 4.0) license, which 
permits others to distribute, remix, adapt, build upon this work non-commercially, and license their derivative works on different terms, provided the original work is properly cited, appropriate credit is given, any changes made indicated, and the use is non-commercial. See: http://creativecommons.org/licenses/by-nc/4.0/.

\section{ORCID iDs}

Aduragbemi Banke-Thomas http://orcid.org/0000-0002-4449-0131

Cephas Ke-on Avoka http://orcid.org/0000-0002-7298-3670

\section{REFERENCES}

1 UNICEF, WHO, World Bank, UNPD. A neglected tragedy: the global burden of stillbirths. New York: United Nations Children's Fund, 2020: 1-90.

2 United Nations. Sustainable development goals: 17 goals to transform our world [Internet]. Sustainable development goals, 2016. Available: http://www.un.org/sustainabledevelopment/sustainabledevelopment-goals/

3 Lawn JE, Blencowe H, Oza S, et al. Every newborn: progress, priorities, and potential beyond survival. Lancet 2014;384:189-205.

4 Lawn JE, Blencowe $\mathrm{H}$, Waiswa $\mathrm{P}$, et al. Stillbirths: rates, risk factors, and acceleration towards 2030. Lancet 2016;387:587-603.

5 Smith GCS. Prevention of stillbirth. Obstet Gynecol 2015;17:183-7.

6 WHO, UNFPA, UNICEF, Averting Maternal Deaths and Disabilities. Monitoring emergency obstetric care: a handbook. Geneva, Switzerland: WHO Press, 2009.

7 Yakoob MY, Ali MA, Ali MU, et al. The effect of providing skilled birth attendance and emergency obstetric care in preventing stillbirths. BMC Public Health 2011;11 Suppl 3:S7.

8 Thaddeus S, Maine D. Too far to walk: maternal mortality in context. Soc Sci Med 1994;38:1091-110.

9 Banke-Thomas A, Balogun M, Wright O, et al. Reaching health facilities in situations of emergency: qualitative study capturing experiences of pregnant women in Africa's largest megacity. Reprod Health 2020;17:145.

10 Banke-Thomas A, Wright K, Collins L. Assessing geographical distribution and accessibility of emergency obstetric care in subSaharan Africa: a systematic review. J Glob Health 2019;9:010414.

11 van Duinen AJ, Adde HA, Fredin O, et al. Travel time and perinatal mortality after emergency caesarean sections: an evaluation of the 2-hour proximity indicator in Sierra Leone. BMJ Glob Health 2020;5:e003943

12 Lohela TJ, Campbell OMR, Gabrysch S. Distance to care, facility delivery and early neonatal mortality in Malawi and Zambia. PLoS One 2012;7:e52110.

13 Niyitegeka J, Nshimirimana G, Silverstein A, et al. Longer trave time to district hospital worsens neonatal outcomes: a retrospective cross-sectional study of the effect of delays in receiving emergency cesarean section in Rwanda. BMC Pregnancy Childbirth 2017; $17: 242$

14 Wariri O, Onuwabuchi E, Alhassan JAK, et al. The influence of travel time to health facilities on stillbirths: a geospatial casecontrol analysis of facility-based data in Gombe, Nigeria. PLoS One 2021;16:e0245297.

15 LASG. Abstract of local government statistics. Ikeja: LASG, 2019.

16 Olajide OA, Agunbiade ME, Bishi HB. The realities of Lagos urban development vision on livelihoods of the urban poor. Journal of Urban Management 2018;7:21-31.

17 Atubi AO. An evaluation of transport infrastructure in Lagos state, Nigeria. Journal of Geography and Earth Science 2013;1:9-18.

18 Aigbe G, Ogundele F, Aliu I. Road facility availability and maintenance in Lagos state, Nigeria. British Journal of Arts and Social Sciences 2012;4:135-9.

19 Kawakatsu Y, Aiga H, Ubani O, et al. Socioeconomic barriers to facility-based delivery in urban poor communities of Lagos: wealth, linguistic capacity, and residential area. Health Policy OPEN 2020;1:100019.

20 Okunowo AA, Smith-Okonu ST. The trend and characteristics of stillbirth delivery in a university teaching hospital in Lagos, Nigeria. Ann Afr Med 2020;19:221.

21 Okonofua FE, Ntoimo LFC, Ogu R, et al. Prevalence and determinants of stillbirth in Nigerian referral hospitals: a multicentre study. BMC Pregnancy Childbirth 2019;19:533.

22 Salazar M, Vora K, Costa AD. Bypassing health facilities for childbirth: a multilevel study in three districts of Gujarat, India. Glob Health Action 2016;9:32178.

23 Stein DT, Golub G, Rothschild CW. Bypassing high-quality maternity facilities: evidence from pregnant women in peri-urban Nairobi. Health Policy and Planning 2020:czaa092.

24 Mubiri P, Kaijo D, Okuga M, et al. Bypassing or successful referral? a population-based study of reasons why women travel far for childbirth in Eastern Uganda. BMC Pregnancy Childbirth 2020;20:497.

25 Rudolfson N, Gruendl M, Nkurunziza T, et al. Validating the global surgery geographical accessibility indicator: differences in modeled versus patient-reported travel times. World J Surg 2020;44:2123-30.

26 Banke-Thomas A, Wong KLM, Ayomoh Fl, et al. "In cities, it's not far, but it takes long": comparing estimated and replicated travel times to reach life-saving obstetric care in Lagos, Nigeria. BMJ Glob Health 2021;6:e004318.

27 Asiyanbola RA, Osoba SB, Adewale SS. Road traffic administration and management in the third World mega-city: Lagos, Nigeria. International Journal of Development and Sustainability 2012:1:490-509.

28 National Population Commission, ICF International. Nigeria demographic and health survey 2018. Abuja, Nigeria and Rockville, Maryland, USA: National Population Commission, ICF International, 2019. https://dhsprogram.com/pubs/pdf/FR359/FR359.pdf

29 Leys C, Ley C, Klein O, et al. Detecting outliers: do not use standard deviation around the mean, use absolute deviation around the median. J Exp Soc Psychol 2013;49:764-6.

30 Buys P, Deichmann U, Wheeler D, Development Research Group World Bank. Road network upgrading and overland trade expansion in Sub-Saharan Africa [Internet]. Washington D.C; (World Bank Policy Research Working Paper). Report No.: WPS4097, 2006. Available: https://documents1.worldbank.org/curated/en/ 441351468194327279/pdf/wps4097.pdf

31 Aliyu AA, Amadu L. Urbanization, cities, and health: The challenges to Nigeria - A review. Ann Afr Med 2017;16:149-58.

32 Ravelli ACJ, Jager $\mathrm{KJ}$, de Groot $\mathrm{MH}$, et al. Travel time from home to hospital and adverse perinatal outcomes in women at term in the Netherlands. BJOG 2011;118:457-65.

33 WHO, UNICEF, UNFPA, World Bank Group, UNDP. Trends in maternal mortality 2000 to 2017: estimates by WHO, UNICEF, UNFPA, World Bank group and the United Nations population division. Geneva: World Health Organization, 2019: 1-119. https:// www.unfpa.org/sites/default/files/pub-pdf/Maternal_mortality_report. pdf

34 Radovich E, Banke-Thomas A, Campbell OMR, et al. Critical comparative analysis of data sources toward understanding referral during pregnancy and childbirth: three perspectives from Nigeria. BMC Health Serv Res 2021;21:1:927.

35 Mucunguzi S, Wamani H, Lochoro P, et al. Effects of improved access to transportation on emergency obstetric care outcomes in Uganda. Afr J Reprod Health 2014;18:87-94.

36 Banke-Thomas A, Wright K, Sonoiki O, et al. Multi-stakeholder perspectives on access, availability and utilization of emergency obstetric care services in Lagos, Nigeria: a mixed-methods study. $J$ Public Health Afr 2017:8:717.

37 Banke-Thomas A, Wong KL, Collins L, et al. An assessment of geographical access and factors influencing travel time to emergency obstetric care in the urban state of Lagos, Nigeria. Health Policy Plan 2021;00. doi:10.1093/heapol/czab099. [Epub ahead of print: 23 Aug 2021]. 